\title{
Response of the Equatorial Atlantic Cold Tongue to Stratospheric Aerosol Geoengineering
}

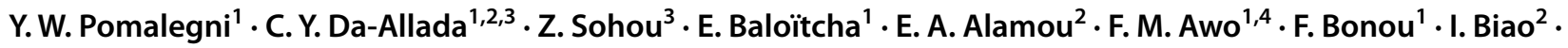

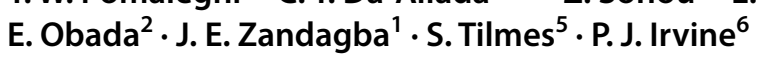

Received: 28 August 2021 / Revised: 20 December 2021 / Accepted: 25 December 2021 / Published online: 17 January 2022

(c) The Author(s) 2022

\begin{abstract}
By increasing Earth-atmosphere system albedo, Stratospheric Aerosol Geoengineering (SAG) using sulfur dioxide is an artificial potential means, with the goal to mitigate the global warming effects. In this study, we used the simulations from Geoengineering Large Ensemble project realized under the climate change scenario of Representative Concentration Pathway 8.5 (RCP8.5), to investigate the potential impact of SAG on the Sea Surface Temperature (SST) in Equatorial Atlantic Cold Tongue (EACT) and the physical processes driving these changes. Results reveal that in the EACT region, under RCP8.5, SST warms significantly (compared to present-day climate) with a maximum of $1.7^{\circ} \mathrm{C}$ in July, and this increase in SST is mainly due to the local processes related to the weakening of vertical mixing at the base of the mixed layer. This reduction of the vertical mixing is associated to the diminution of the vertical shear from July to April and to the increase of ocean stratification from May to June. However, under SAG, SST decreases significantly throughout the year (compared to present-day climate) with a maximum cooling of $-0.4{ }^{\circ} \mathrm{C}$ in the cold tongue period (May-June). This SST cooling is mainly associated with the non-local processes related to intensification of the westerly equatorial Atlantic wind stress. Finally, results show that the use of SAG to offset all global warming under RCP8.5 results in a slight over compensation of SST in the EACT region.
\end{abstract}

Keywords Climate change $\cdot$ Equatorial Atlantic Cold Tongue $\cdot$ Sea surface temperature $\cdot$ Stratospheric aerosol geoengineering $\cdot$ Westerly winds

\section{Introduction}

Among diverse theoretical approaches to limit the effects of the increase of global warming, solar radiation modification (SRM) aims to reduce some amount of incoming solar short-wave radiation reaching Earth's surface and has been

Y. W. Pomalegni

yveswilfriepomalegni@yahoo.com

ICMPA-UNESCO Chair/UAC, Cotonou, Benin

LaGEA/ENSTP/UNSTIM, Abomey, Benin

3 LHMC/IRHOB, Cotonou, Benin

4 Department of Oceanography, Nansen-Tutu Centre for Marine Environmental Research, University of Cape Town, Cape Town, South Africa

5 Atmospheric Chemistry, Observations, and Modeling Laboratory, National Center for Atmospheric Research, Boulder, CO, USA

6 John A. Paulson School of Engineering and Applied Sciences, Harvard University, Cambridge, MA, USA indicated as a suplementary approach for counteracting the effects of global warming (e.g., Crutzen 2006; Kravitz et al. 2013; Visioni et al. 2020). The application of SRM using stratospheric aerosol geoengineering (SAG), which would involve injections of sulfur dioxide into the stratosphere in order to reduce the global mean surface temperature, the interhemispheric, and equator-to-pole temperature gradients at their 2020 levels under Representative Concentration Pathway 8.5 scenario, has been suggested to be one method that can quickly cool planetary surface temperature (Tilmes et al. 2018; Robock et al. 2008; Kravitz et al. 2011; Jones et al. 2018; MacMartin et al. 2017). While SAG is generally effective in reducing the effects of global warming (climate change), it can be over effective in offsetting hydrological change, meaning that if deployed to offset all warming it can produce a net weakening of the hydrological cycle (Tilmes et al. 2013; Irvine et al. 2019; Kravitz et al. 2018). This also applies at the regional scale, for example, Da-Allada et al. 2020 showed that under global warming, there is an increase (relatively to the present-day climate) in the monsoonal precipitation in the western African region, 
whereas in a scenario where SAG offsets all warming there is a significant net reduction in precipitation. Their study revealed that the decrease in precipitation in this region is related to changes in the monsoon circulation (mainly the weakening of the southeasterly trade winds). By modifying the trade winds, the use of SAG could also affect the tropical Atlantic Ocean circulation and sea surface temperature (SST) in the region.

SST in the tropical Atlantic, particularly in the Equatorial Atlantic Cold Tongue (EACT) region, which is strongly linked with the West African monsoon (Caniaux et al. 2011), plays an important role on the regional climate (Jouanno et al. 2011; Planton et al. 2018). In the EACT region, an important decrease of the SST (by $5{ }^{\circ} \mathrm{C}$ to $7{ }^{\circ} \mathrm{C}$ ) is developed during late boreal spring/early boreal summer (Merle et al. 1979). SST variability in the EACT is complex and depends on several processes such as atmospheric heat fluxes, advection, the entrainment term, and vertical mixing at the base of the mixed layer (Foltz et al. 2003; Peter et al. 2006; Wade et al. 2011; Giordani et al. 2013). But most studies have shown that vertical mixing at the base of the mixed layer is the main process explaining the variability of the SST in the EACT (Jouanno et al. 2011; Planton et al. 2018); Hummels et al. 2013; Shlundt et al. 2014): a strong vertical mixing induced a cooling of the SST while weak vertical mixing explained a warming. In addition, it has been demonstrated that the vertical mixing in this region is due to the vertical shear of the horizontal currents in the presence of weak stratification (Jouanno et al. 2011). Furthermore, past studies have also indicated that, the remote wind forcing (non-local processes) in the Western Equatorial Atlantic (WEA) may also drive SST variability in the EACT (Planton et al. 2018; Ding et al. 2010; Burls et al. 2012). An intensification of winds in the WEA could induce upwelling Kelvin waves that propagate eastward and trigger the rising of the thermocline (represented by the $20{ }^{\circ} \mathrm{C}$ isotherm or D20) to the East, and vice versa for a weakening of winds (e.g., Castaño-Tierno et al. 2018). This movement of the thermocline leads to a reduction (augmentation) in the sea surface height (SSH) and SST in the EACT region (Planton et al. 2018; Marin et al. 2009; Nnamchi et al. 2020). Thus, as the EACT region is largely related to the West African summer monsoon precipitation which is of key importance for agriculture productivity and water availability, it is essential to study the changes of SST under GLENS in this region. Then, the goal of this study is to use the simulations of the stratospheric aerosol geoengineering large ensemble (GLENS) project (Tilmes et al. 2018) to investigate the impact of SAG on SST and to determine the physical mechanisms responsible for SST changes in the EACT.

The remainder of this work is structured as follows: Sect. 2 describes the methods, Sect. 3 presents the results, and Sect. 4 provides the conclusion and discussion.

\section{Methods}

The National Center for Atmospheric Research Community Earth System Model (CESM1) simulations of the GLENS project (Tilmes et al. 2018) are used to assess the potential impact of SAG on SST in EACT. CESM1 uses the Parallel Ocean Program version 2 (POP2) for its oceanic component, which has a spatial resolution $0.33^{\circ}$ latitude $\times 1.125^{\circ}$ longitude and 60 vertical layers (Danabasoglu et al. 2012). For the atmospheric component, the Whole Atmosphere Community Climate Model (WACCM) is used, with a horizontal resolution of $0.9^{\circ}$ in latitude by $1.25^{\circ}$ in longitude (Mills et al. 2017). In GLENS, two sets of experiments were performed under the RCP8.5 future greenhouse gas forcing scenario. First, the RCP8.5 simulations with 20 ensemble members that were performed for the period 2010-2030, while three of them were extended to cover the period 2010-2097. Second, the SAG simulations, conducted over the period from 2020 to 2099, that in addition to the RCP8.5 experiments injected sulfur dioxide $\left(\mathrm{SO}_{2}\right)$ into the stratosphere at four different latitudes simultaneously $\left(15^{\circ} \mathrm{N}\right.$ and $15^{\circ} \mathrm{S}$ at $25 \mathrm{~km}$, $30^{\circ} \mathrm{N}$ and $30^{\circ} \mathrm{S}$ at $22.8 \mathrm{~km}$, all at longitude of $180^{\circ}$ ) with the aim to keep the global mean temperature, the interhemispheric temperature gradient, and the equator-to-pole temperature gradient at 2020 levels (Tilmes et al. 2018; Kravitz et al. 2017). As in previous studies (Da-Allada et al. 2020; Pinto et al. 2020; Karami et al. 2020), we use monthly model results and three members reaching towards the end of the twenty-first century. In this analysis, a 20 -year average is calculated for the different simulations, with years ranging from 2010 to 2029 for the baseline (current climate) simulations (BSL) and 2050 to 2069 for the RCP8.5 and GLENS simulations. To assess the validity of the model, we compare SSTs from the historical simulation (HIST) (Tilmes et al. 2018) to the Extended Reconstructed Sea Surface Temperature Version 4 (Huang et al. 2014) over the common period 1990-2009 (20-years). The vertical structure of simulated ocean temperatures is also compared with in-situ temperatures from the Prediction and Research Moored Array in the Tropical Atlantic (PIRATA) moored buoys at $0^{\circ} \mathrm{N}-10^{\circ} \mathrm{W}$ (Bourlès et al. 2008), which is located in our study region. PIRATA moorings measure subsurface temperatures at 11 depths between 1 and $500 \mathrm{~m}$ with $20 \mathrm{~m}$ spacing in the upper $140 \mathrm{~m}$. The period used for this validation is 1997-2009 and corresponds to the period for which in situ data are available.

To examine the changes under global warming, the difference RCP8.5 minus BSL is calculated, while to assess the changes under SAG, the difference GLENS minus BSL is determined. In addition, the statistical significance using a two-sided t-test is calculated for the SST changes, and for evaluating the error estimate of SST changes, the standard error is used. To explain seasonal effects of SST changes in 
EACT (Fig. 1), we evaluate the changes in local processes (mainly in the atmospheric heat fluxes and the vertical mixing) and the non-local processes (principally changes in the WEA $\left(40^{\circ} \mathrm{W}-10^{\circ} \mathrm{W}, 2^{\circ} \mathrm{S}-2^{\circ} \mathrm{N}\right)$ wind stress). Thus, to assess the role of atmospheric heat fluxes in SST changes, changes in the total or net heat flux (NHF), which are defined as the sum of solar shortwave, latent heat flux, sensible heat flux, and longwave radiation are examined. To evaluate the contribution of the vertical mixing in the SST (e.g., Jouanno et al. 2011; Planton et al. 2018), changes in the vertical shear of the horizontal currents and the stratification changes are analyzed. The vertical shear squared $\mathrm{Sh}^{2}$ is calculated following Da-Allada et al. (2017):

$\mathrm{Sh}^{2}=\left(\frac{\partial U}{\partial z}\right)^{2}+\left(\frac{\partial V}{\partial z}\right)^{2}$

where $U$ is the zonal current and $V$ the meridional current. For the density stratification, the Brunt-Väisälä frequency $N^{2}(T, S)$ is used and calculated (Da-Allada et al. 2017; Maes and O'kane 2014) as follows:

$N^{2}(T, S)=\frac{-g}{\rho} \frac{\partial \rho}{\partial z} \approx\left(\mathrm{g} \alpha \frac{\partial T}{\partial z}-\mathrm{g} \beta \frac{\partial S}{\partial z}\right)$,

where $T$ and $S$ are the vertical profiles of temperature and salinity, respectively, $\alpha$ is the thermal expansion coefficient, $\beta$ is the haline contraction coefficient, $g$ is the gravity, $\rho$ is the density, $\frac{\partial}{\partial z}$ denotes the vertical gradient operator, and $z$ the upward coordinate, and $\alpha=1.5 \times 10^{-4}{ }^{\circ} \mathrm{C}^{-1} . \beta=7.9 \times$ $10^{-4} \mathrm{ppt}^{-1}$ (Halkides and Lee 2011), and $g=9.81 \mathrm{~m} \mathrm{~s}^{-2}$. To investigate the role of remote forcing (non-local processes) wind stress changes in WEA, D20 and SSH changes are examined.

To provide a quantitative analysis in this study, the mixed layer heat budget is estimated as follows (see Mohan et al. 2021 or Da-Allada et al. 2021):

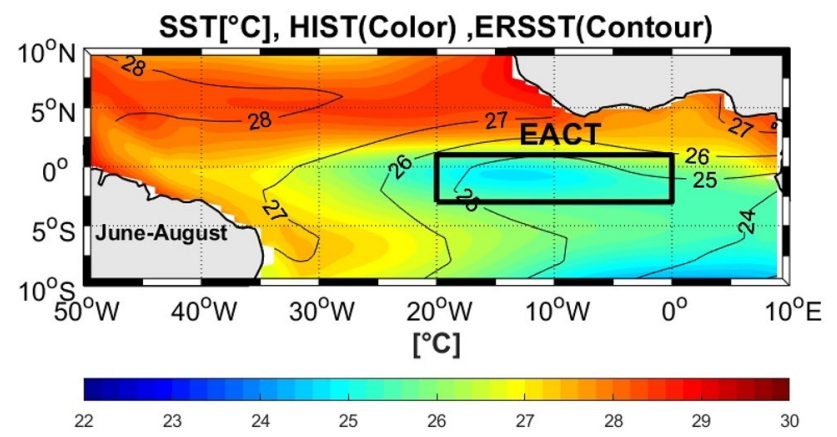

Fig. 1 June-August averaged (1990-2009) HIST simulations (color shading) and ERSST observational (contours) SST $\left({ }^{\circ} \mathrm{C}\right)$ and spatial delimitations of the box EACT used in this study

$$
\begin{aligned}
\underbrace{\frac{\partial\langle T\rangle}{\partial t}}_{\text {TOT }}= & \underbrace{\frac{Q_{\text {net }}-Q_{\mathrm{pen}}}{\rho \mathrm{Cph}}}_{\text {NHF }}-\underbrace{\left\langle u \cdot \partial_{x} T\right\rangle-\left\langle v \cdot \partial_{y} T\right\rangle}_{\mathrm{ADH}} \\
& -\underbrace{\left\langle w \cdot \partial_{z} T\right\rangle}_{\text {ZAD }}-\underbrace{\frac{1}{h} \frac{\partial h}{\partial t}\left(\langle T\rangle-T_{z=-h}\right)}_{\text {ENT }}+R
\end{aligned}
$$

With $\langle\bullet\rangle=\frac{1}{h} \int_{-h}^{0} \bullet \mathrm{d} z$.

$T$ is the model potential temperature, $\rho$ is the surface reference density (set to $1021 \mathrm{~kg} \mathrm{~m}^{-3}$ as in Da-Allada et al. 2021), $C_{\mathrm{p}}$ is the heat capacity, (set to $3984 \mathrm{~J} \mathrm{~kg}^{-1}{ }^{\circ} \mathrm{C}^{-1}$ as in Da-Allada et al. 2021 or in Wade et al. 2011), $h$ is the mixed layer depth (MLD), $Q_{\text {net }}$ is the net surface heat flux, $Q_{\text {pen }}$ is the penetrative loss of shortwave radiation to the oceanic mixed layer, $(u, v, w)$ the zonal, meridional, and vertical components of the velocity, and $\mathrm{R}$ is the residual term that includes lateral diffusion, vertical mixing, and errors made on estimation of the different terms of the heat budget (Eq. 1). $Q_{\text {net }}$ is estimated as $Q_{\text {net }}=\mathrm{SW}-(\mathrm{LW}+\mathrm{LH}+\mathrm{SH})$, where SW is the solar shortwave radiation, LW, the net longwave radiation, $\mathrm{LH}$ the latent heat flux, $\mathrm{SH}$ the sensible heat flux while the $Q_{\text {pen }_{-h}}$ is calculated as $Q_{\mathrm{pen}}=0.47 \cdot \mathrm{SW}\left(V_{1} e^{\frac{-h}{\varepsilon_{1}}}+V_{2} e^{\frac{-h}{\varepsilon_{2}}}\right)$ with $\varepsilon_{1}$ and $\varepsilon_{2}$ the attenuation depths of long visible, short visible, and ultraviolet wavelengths. We use the values of $V_{1}, V_{2}, \varepsilon_{1}$, and $\varepsilon_{2}$ as 0.39 , $0.69,1.52$, and 18.9 , respectively, as used in previous studies (e.g., Mohan et al. 2021). In the Eq. (3), the left-hand side represents the total temperature tendency (TOT) which is driven from left to right by the storage of net air-sea heat flux (NHF) in the mixed layer, horizontal advection (ADH) including zonal and meridional advection, the vertical advection (ZAD), and the entrainment (ENT) at the base of the mixed layer. Hereafter, we define oceanic processes under the term $\mathrm{OCP}(\mathrm{OCP}=\mathrm{ADH}+\mathrm{ZAD}+\mathrm{ENT}+\mathrm{R})$ which could be also estimated as OCP $=$ TOT-NHF.

\section{Results}

\subsection{Evaluation of Model Performance in Simulating the SST in EACT}

Figure 2 shows the seasonal cycle of the simulated SST (Fig. 2b) compared to that of the observational product ERSST (Fig. 2a) and their difference (Fig. 2c). The SST cooling starts from May and reaches its maximum in August at $10^{\circ} \mathrm{W}$ both in the model and in the observations. This cooling persists until November but with a diminution of its intensity. From December to April, the SST warmed in the equatorial Atlantic in model and observations. Overall, the model reproduced the main 

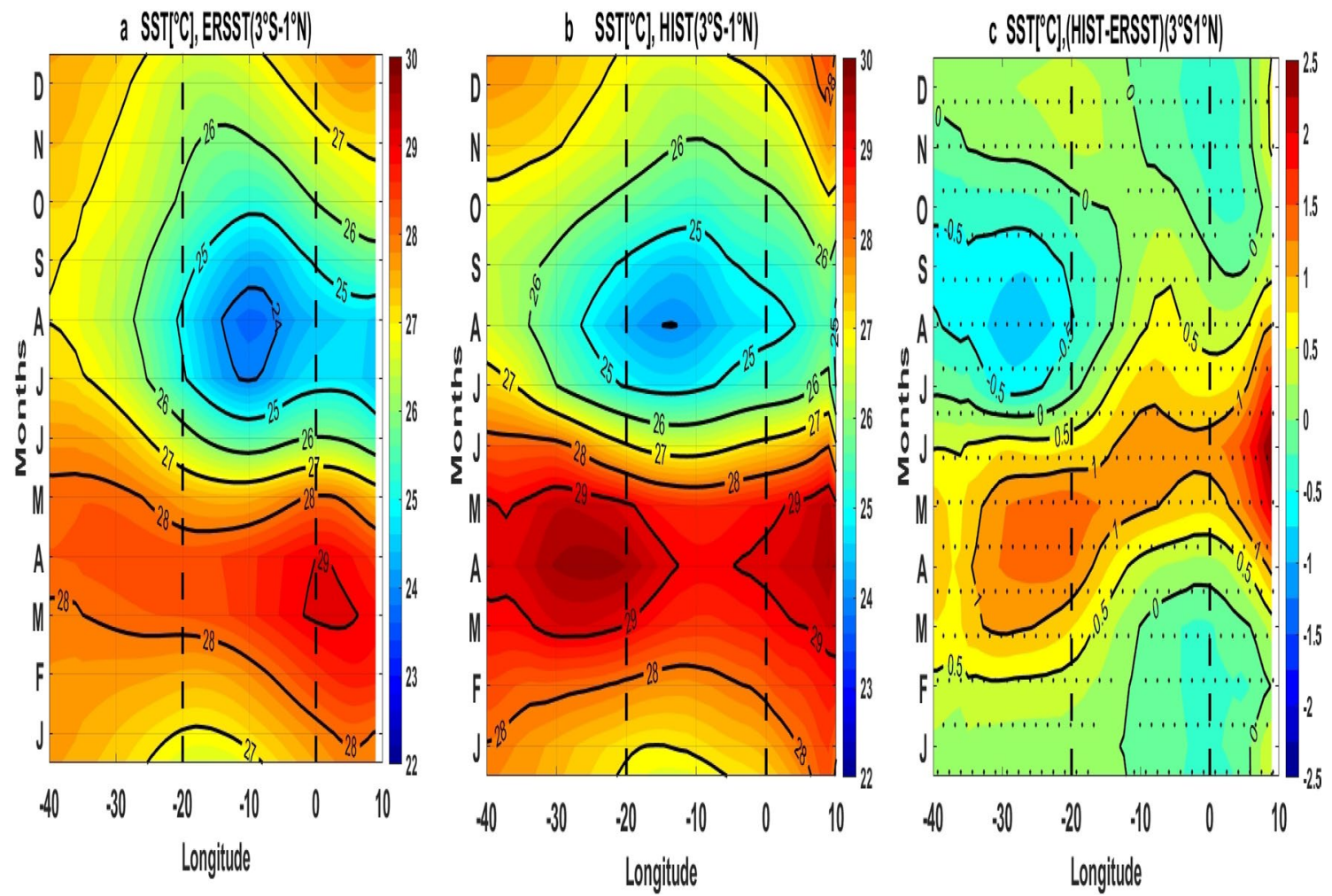

Fig. 2 Longitude-time diagram at $\left(3^{\circ} \mathrm{S}-1^{\circ} \mathrm{N}\right)$ of SST $\left({ }^{\circ} \mathrm{C}\right)$ for the period 1990-2009, computed with a Extended Reconstructed Sea Surface Temperature Version 4 (ERSST.v4) and b model data (HIST), c model SST (HIST) minus observed SST (ERSST). Dashed

characteristics of SST in the EACT region as shown in the observations, although there is a warm bias of about $1{ }^{\circ} \mathrm{C}$ in March-May between $5^{\circ} \mathrm{W}$ and $40^{\circ} \mathrm{W}$ and another slightly warmer bias of approximately $1.5^{\circ} \mathrm{C}$ from the African coast to $5^{\circ} \mathrm{W}$. A cold bias of $-0.5^{\circ} \mathrm{C}$ is located between $20^{\circ} \mathrm{W}$ and $40^{\circ} \mathrm{W}$ from July-October in the model compared to observations. However, this kind of bias is known for most coupled models in the tropical Atlantic and may have several sources including biases in some parameterizations or improperly resolved wind (Richter et al. 2012).

Model temperatures and in-situ temperatures from the PIRATA mooring are compared to verify the capacity of the model to reproduce the subsurface temperature (Fig. 3). This comparison shows that the seasonal cycle of the vertical ocean temperature profile in the HIST simulation and in the PIRATA buoys observations are in good agreement. Other characteristics that are well represented by the model is the position of the thermocline depth (D20). However, the model again has a slight warm bias that extends through the ocean column, meaning that the D20 is slightly deeper compared to PIRATA. Overall, the model has demonstrated its ability to simulate the seasonal time scale of the observations. vertical lines delineate the longitudes of the Equatorial Atlantic Cold Tongue as defined here. The marked points in (c) indicate regions where difference is statistically significant at the $95 \%$ level using the Student's $t$ test

\subsection{Changes in the SST of EACT and Their Drivers}

Figure 4a shows that the seasonal cycle of SST in BSL indicating a warming of the SST from September to April with a maximum value of around $30^{\circ} \mathrm{C}$ obtained in April whereas SST cooling started in May and extends until August with minimum value (around $25^{\circ} \mathrm{C}$ ) found in August. For RCP8.5 and GLENS, the seasonal cycles of SST are similar to that BSL except for some differences in terms of magnitude. The difference between RCP8.5 and BSL is positive throughout the year with a maximum of $1.7^{\circ} \mathrm{C}$ in July, which means that SST is increasing under RCP8.5 (Fig. 4b). This SST increase is smallest in early boreal spring. However, under GLENS, contrary to RCP8.5, the seasonal cycle of the SST changes shows a significant decrease in SST all year long with the maximum decrease of $-0.4{ }^{\circ} \mathrm{C}$ in the Cold Tongue period (May-June) compared to the BSL (Fig. 4b).

To understand the physical processes that explain the SST changes, firstly the role of surface heat fluxes is investigated. The seasonal cycle of the NHF in BSL, which is dominated by solar shortwave radiation and the latent heat flux contributions, is large and positive most of the year but approaches zero in May and June (Fig. 5a). Under RCP8.5, changes in NHF relative to the baseline (RCP8.5-BSL) indicates a 

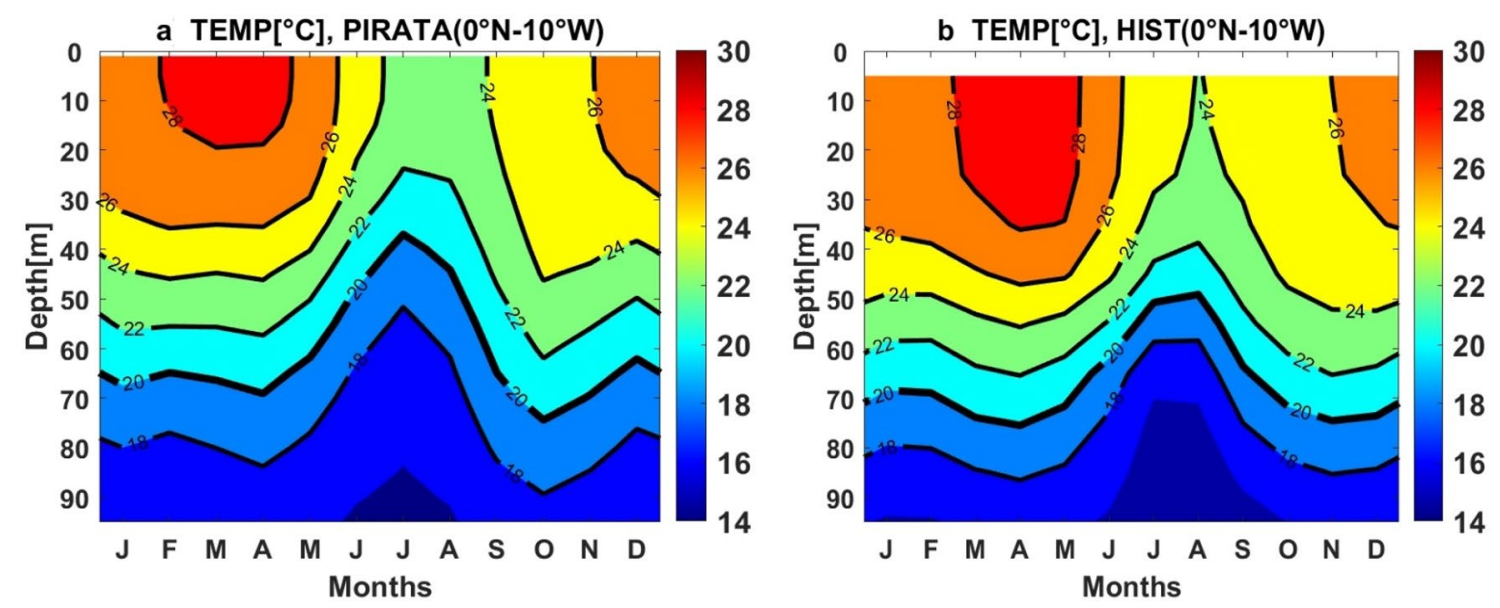

Fig. 3 Comparison between the seasonal cycles of the vertical temperatures structure of the temperature at: $0^{\circ} \mathrm{N}-10^{\circ} \mathrm{W}$ : a PIRATA observations, $\mathbf{b}$ model (b); contours are $18,20,22,24$, and $26{ }^{\circ} \mathrm{C}$ isotherms. The units are ${ }^{\circ} \mathrm{C}$ for temperature and $\mathrm{m}$ for the depth

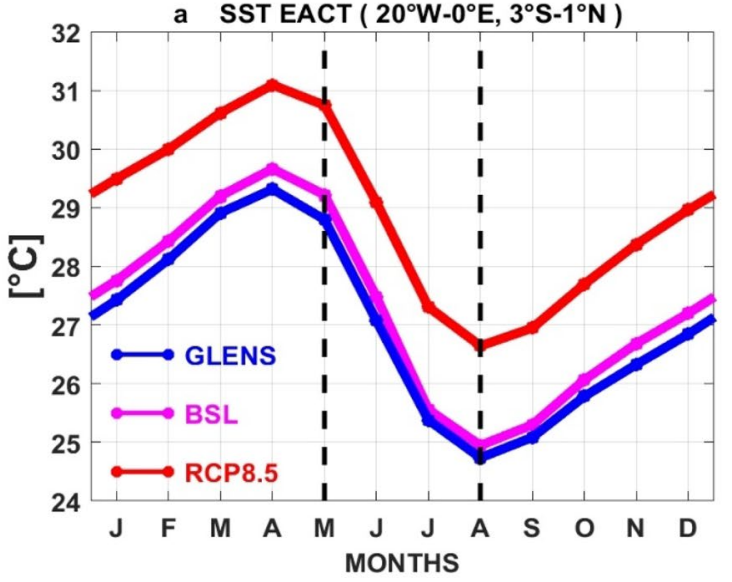

Fig. 4 Seasonal cycles of a SST from RCP8.5 (red), GLENS (blue), BSL (magenta); b SST changes under RCP8.5 (red), under GLENS (blue); the shaded areas represent the standard error of changes in SST. In b the month with a black dot represents the month in which

diminution of NHF from June to March and slightly increase (of NHF) in May, but NHF remains unchanged in April (Fig. 5b). This augmentation of NHF in May is due to the increase in shortwave radiation which is related to the reduction in cloud cover (Cheng et al. 2019). Thus, the atmospheric heat fluxes contribute to explain the SST warming obtained in EACT in May. However, under GLENS, changes in NHF compared to the baseline (GLENS-BSL) show an augmentation of NHF from April to June but remain unchanged from December to March (Fig. 5c). During these periods, the reduction in SST cannot be associated with the atmospheric heat fluxes changes. From July to November, the NHF decreases and this diminution is linked to the reduction of shortwave radiation (due to the use of SAG) and the latent heat flux. Note that the diminution in the latent

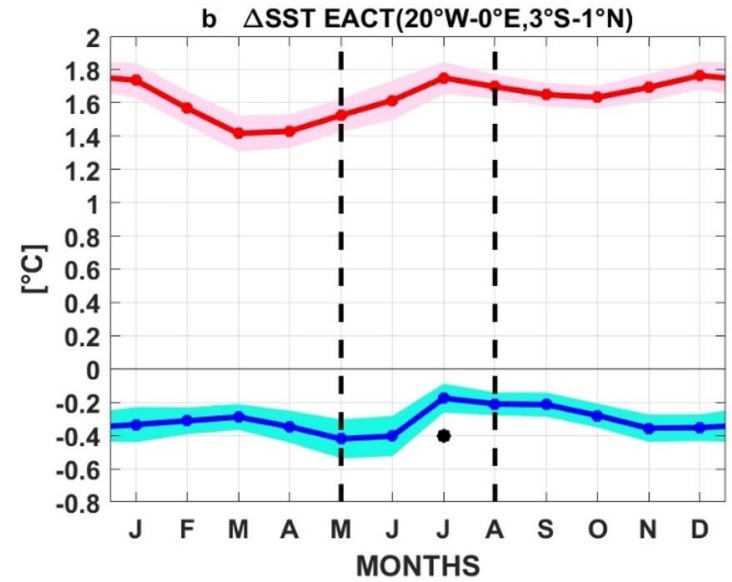

the change in SST is not statistically significant at the 95\% level using the Student $t$ test. The two dashed vertical lines delineate the Equatorial Atlantic Cold Tongue period. The units are in ${ }^{\circ} \mathrm{C}$ (color figure online)

heat flux in the EACT has suggested to be associated with changes in the vertical humidity gradient due to changes in the SST (Planton et al. 2018; Foltz and McPhaden 2006). Thus, during July to November, atmospheric heat fluxes changes contribute to explain the SST cooling in EACT whereas the rest of the year (December to June), the atmospheric heat fluxes do not play a role in the SST reduction.

As explained above, changes in NHF contribute to understand the SST increase only in May under RCP8.5, whereas this term leads to SST decrease from July to November under GLENS. This suggest that ocean dynamics will play an important role in SST changes. Under RCP8.5, Fig. 6a and $\mathrm{c}$ shows that from July to April, changes in stratification and vertical shear of the horizontal currents at the base of the mixed layer indicate a diminution both in these two terms. 

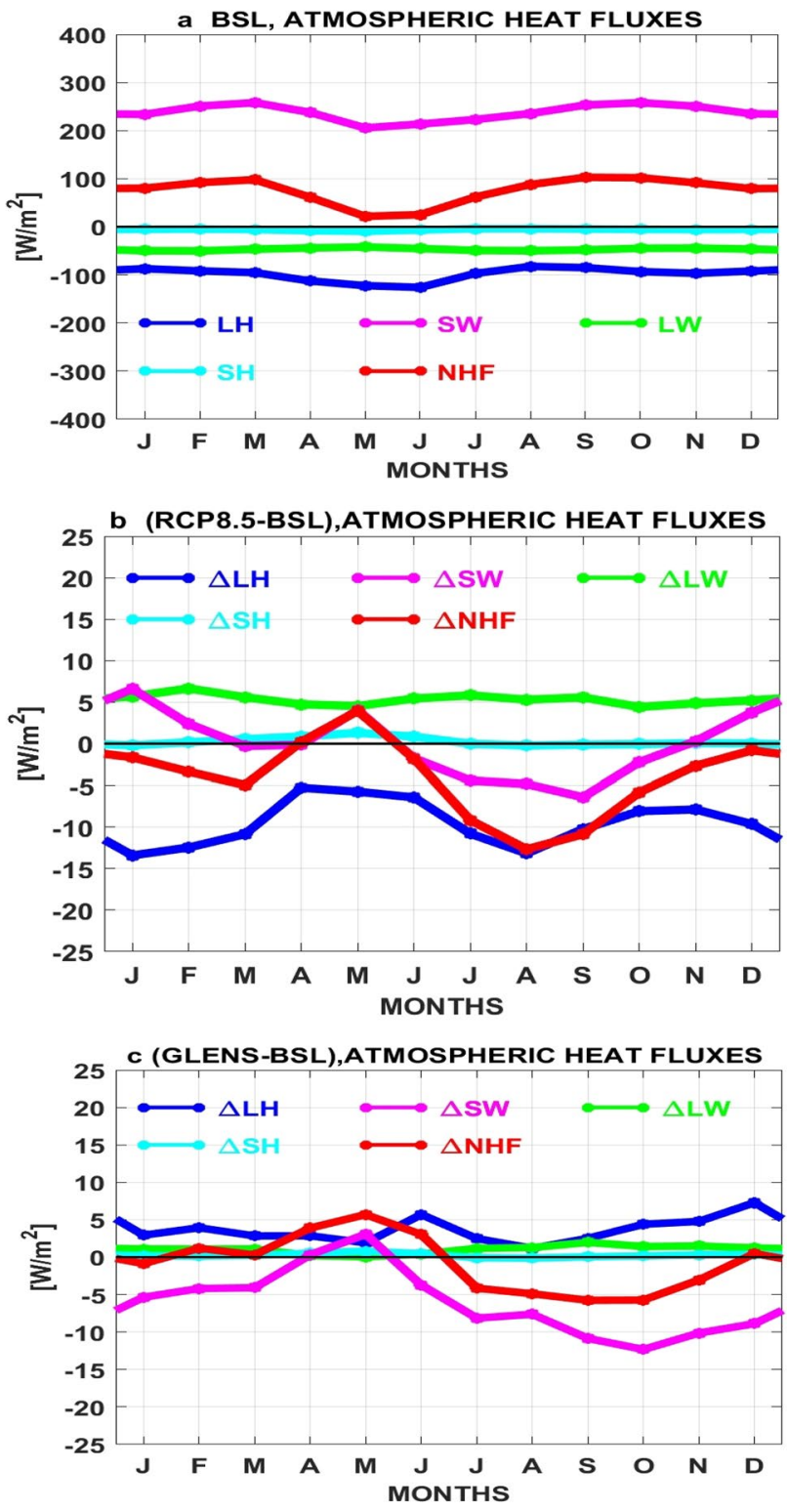

Fig. 5 Seasonal cycles in the EACT region $\left(20^{\circ} \mathrm{W}-0^{\circ} \mathrm{E}, 3^{\circ} \mathrm{S}-1^{\circ} \mathrm{N}\right)$ of a atmospheric flux [longwave (green), shortwave (magenta), sensible heat flux (light blue), latent heat flux (blue), net heat flux (red)], b change in fluxes under RCP8.5, and $\mathbf{c}$ change in fluxes under GLENS (color figure online)

Even though, from July to April, the decrease in stratification could induce vertical mixing augmentation, the reduction in vertical shear at the base of the mixed layer during this same period will actually lead to a decrease in vertical mixing from July to April. This reduction in vertical mixing at the base of the mixed layer limits the mixing between the cold thermocline waters and the warm surface waters, and thus, leading to the warming of the SST in EACT. In addition, the fact that the decrease in vertical shear of the horizontal currents at the base of the mixed layer is more important in
July and corresponds to the month that the increase in SST is maximum, indicates the major role played by vertical shear in vertical mixing as previously mentioned in certain studies (Jouanno et al. 2011). The rest of the year, May to June (Cold Tongue period), changes in both stratification and the vertical shear of horizontal currents show an increase in these two terms, but the magnitude of the augmentation in stratification is more important than in the vertical shear. The enhanced stratification results in a reduction in vertical mixing at the base of the mixed layer, which further leads to an increase of SST in the EACT region (Fig. 7a). Finally, throughout the year, the weakening of the vertical mixing at the base of the mixed layer contributes to the SST warming under RCP8.5. However, under GLENS, for the entire year, changes (compared to the baseline) in stratification and vertical shear of horizontal currents at the base of the mixed layer decrease or remain unchanged except in May when the shear increases slightly (Fig. 6b, d). This slight increase in vertical shear at the base of the mixed layer in May contributes to a slight increase in vertical mixing, and this allows the (slight) SST cooling in EACT during this month (Fig. 7b). Thus, contrary to RCP 8.5 where the vertical mixing plays an important role in the SST warming, under GLENS, the role of this term is weak to explain the SST cooling.

To go further into the causes of the SST changes, a heat budget is computed. In baseline simulation, the seasonal cycle of the total temperature tendency (TOT) is positive from September to April which corresponds to the period of SST increase and negative from May to August that correspond to the period of SST decrease (Figs. 4b, 8a). The SST increase is explained by the positive net air-sea heat flux due to the shortwave radiation (NHF; Fig. 8a) while the decrease in SST is caused by the negative oceanic processes (OCP; Fig. 8a). The OCP decomposition indicates that this term is mainly controlled by the residual term (R, Fig. 9a). It has been shown that, in the EACT region, the lateral diffusion is negligible and the R term is largely dominated by the vertical mixing (Wade et al. 2011; Jouanno et al. 2011). Under RCP8.5 (relative to BSL), the modifications in NHF and OCP terms leading to weak changes in TOT (Fig. 8b). NHF changes are almost negative all year except in May, and this term contributes to negative SST changes. Contrary to NHF, OCP changes are positive all the year, and this term leads to positive SST changes. These results suggest that, SST increase under RCP8.5 is largely related to the OCP modification. Changes in OCP are mainly caused by changes in R (Fig. 9b) which are dominated by the modification in the vertical mixing (as explain above). This term shows an important contribution to increase SST in August (about $0.6^{\circ} \mathrm{C} /$ month) where the diminution in vertical shear of the horizontal currents is important (Fig. 6a). All these results obtained here are in agreement with those described above. 

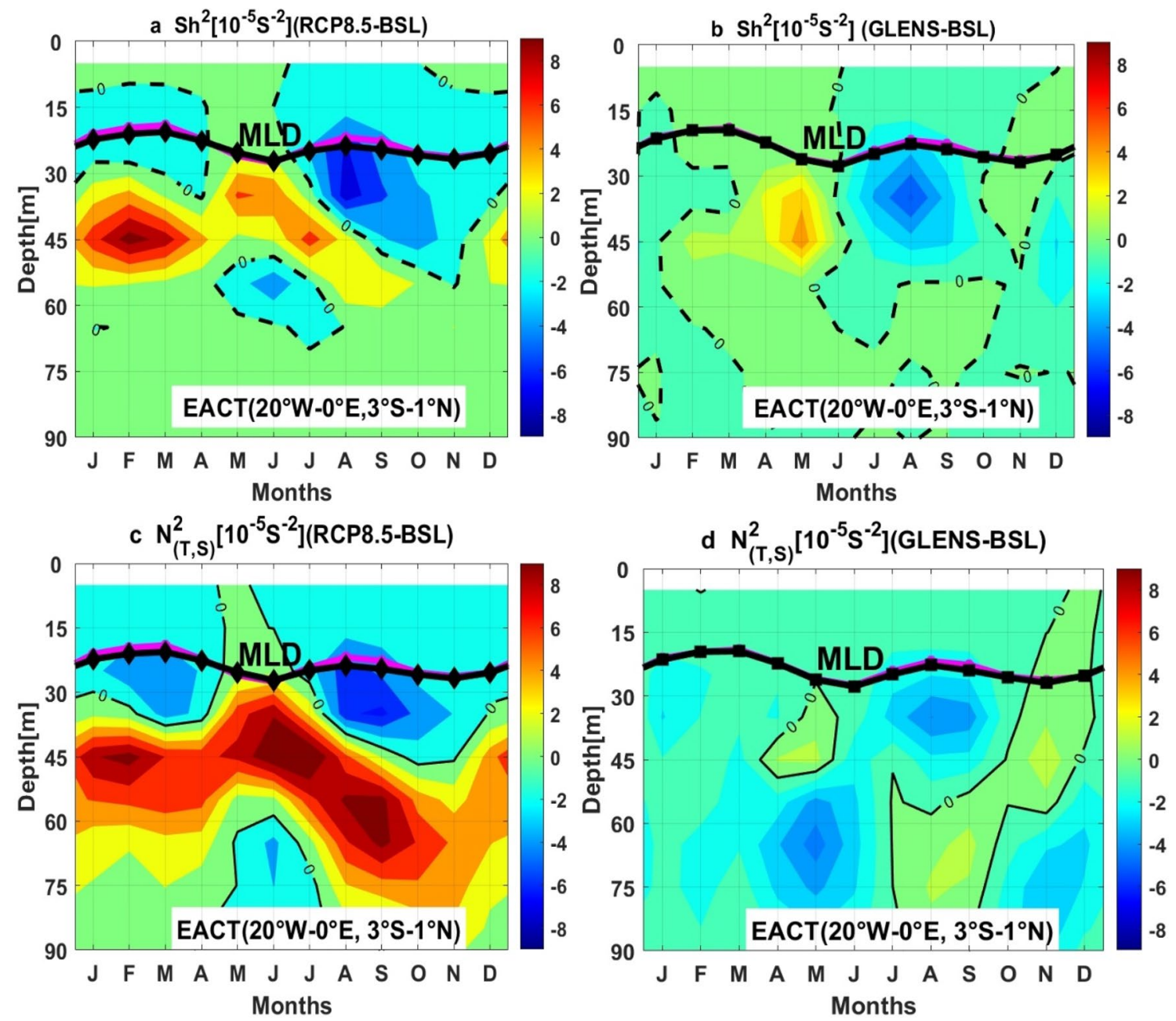

Fig. 6 Seasonal evolution of changes relative to the baseline of vertical profiles at EACT in vertical shear a under RCP8.5, b under GLENS and in stratification, $\mathbf{c}$ under RCP8.5 and $\mathbf{d}$ under GLENS

and the Mixed Layer Depth (black diamond line for RCP8.5; magenta line for BSL and black square line for GLENS). The units are $10^{-5} \mathrm{~s}^{-2}$

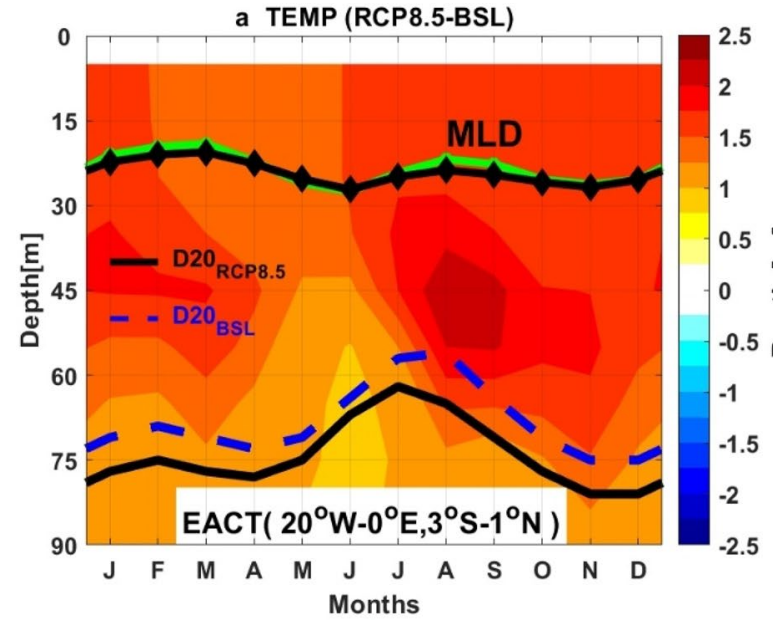

Fig. 7 Time-depth diagram in EACT of changes in sea water temperature in ${ }^{\circ} \mathrm{C}$ (in color shading): a under RCP8.5; $\mathbf{b}$ under GLENS; MLD (black diamond line for RCP8.5; green line for BSL and black

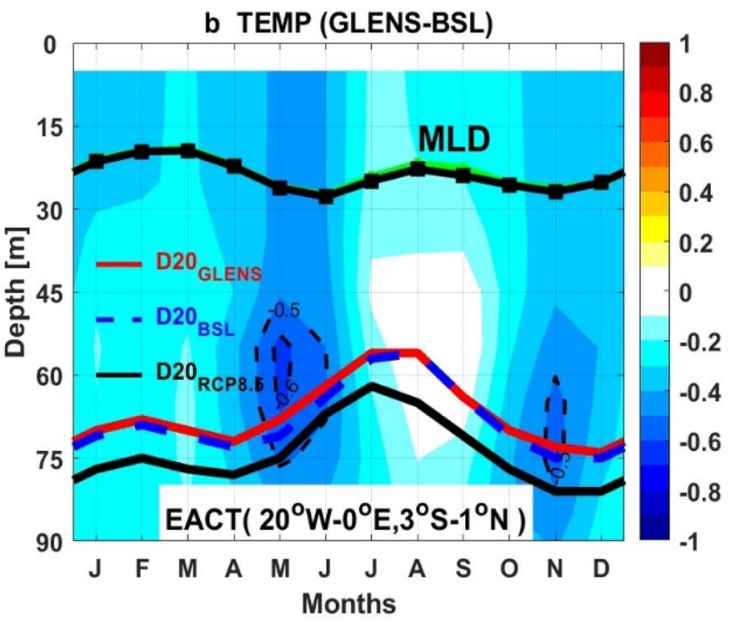

square line for GLENS) and the depth of $20{ }^{\circ} \mathrm{C}$ isotherm (in dashed blue line for BSL, black lines for RCP8.5 and red line for GLENS) (color figure online) 

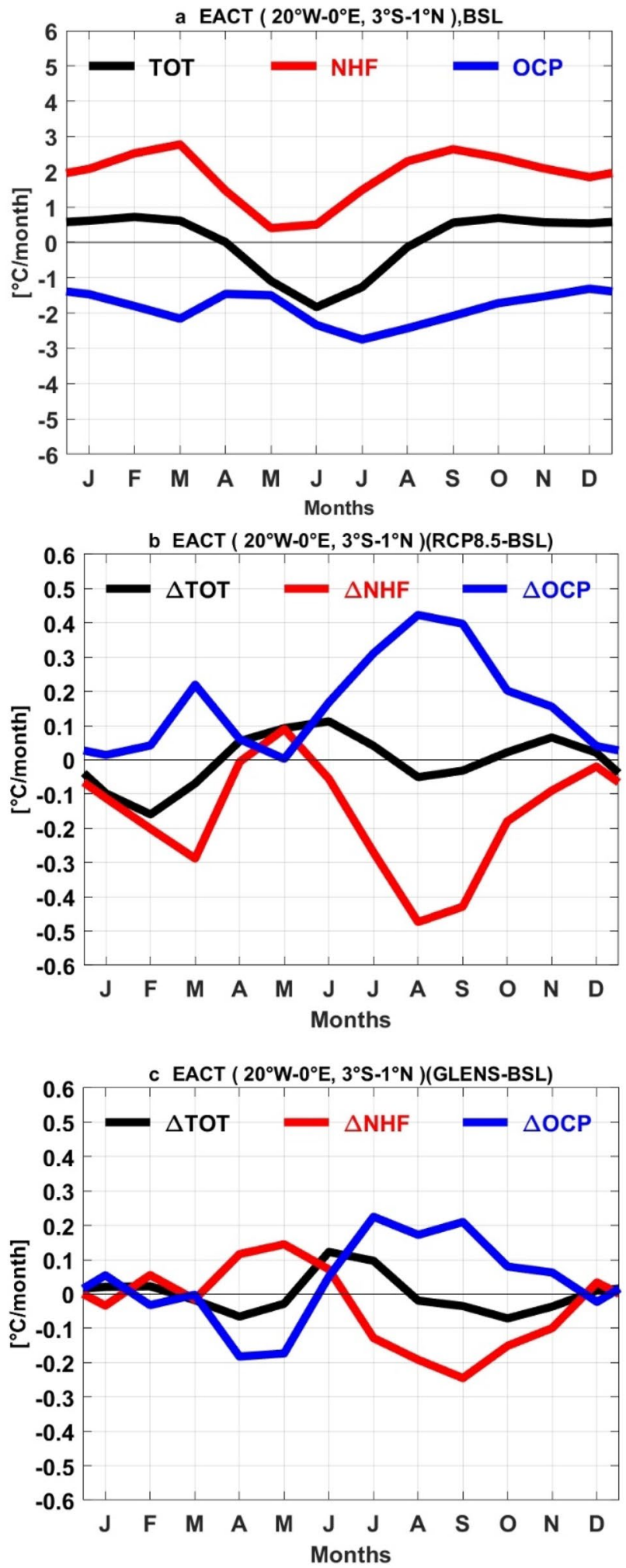

Fig. 8 Seasonal cycle for 2050-2069 of the mixed layer heat budget in the EACT region: a baseline simulation, Total temperature tendency (TOT, black), net air-sea heat flux (NHF, red), oceanic processes (OCP, blue); b under RCP8. 5, changes in total temperature tendency (black), changes in net air-sea heat flux (NHF, red), changes in oceanic processes (OCP, blue); c same as previously but under GLENS (color figure online)
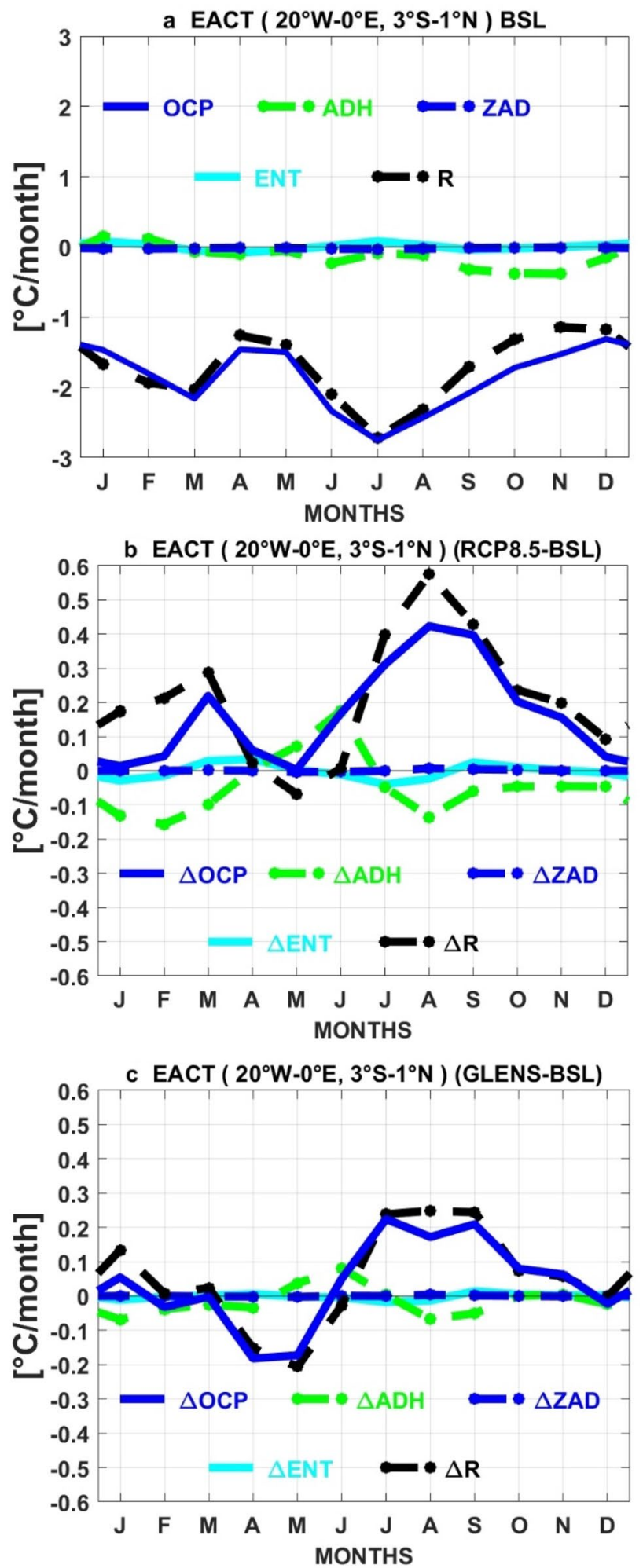

Fig. 9 Same as in Fig. 8 but from the decomposition of oceanic processes. Oceanic processes (OCP, blue); Horizontal advection (ADH, dashed green), vertical advection (ZAD, dashed blue), Entrainment (ENT, light blue), Residual (R, dashed black) 
Under GLENS (relative to BSL), the changes in TOT result from combination of changes in NHF and OCP (Fig. 8c). The amplitude of all these terms are weak compared to those of RCP8.5. Because of reduction in shortwave radiation, changes in NHF show an important diminution from July to November (with a maximum contribution of $-0.24{ }^{\circ} \mathrm{C}$ / month in September), and this helps explain the decrease in SST in this period. The rest of the year, the increase of NHF does not explain the diminution in SST. The maximum OCP augmentation from April to May (approximately $-0.18^{\circ} \mathrm{C} /$ month) is related to the increase in the vertical mixing and tends to explain the SST diminution in this period (Fig. 9c). The rest of the year changes in OCP do not explain the decrease in SST. All these results indicate that local processes do not alone explain the SST decrease and then suggest the importance of the remote forcing to explain the SST change under GLENS. These findings are consistent with those found above.

To conclude the processes that explain the SST changes, the role of non-local processes is now examined. As mentioned above (Sect. 1), WEA wind changes could affect the D20 through equatorial waves and lead to SST changes in the EACT region (Planton et al. 2018; Marin et al. 2009; Nnamchi et al. 2020). Under RCP8.5, we analyze the correlation between wind changes in the WEA and D20 changes and found that there is a weak correlation ( $r=0.38$ not significantly at the $95 \%$ significance level) between these two terms (Fig. 10a). Also a weak correlation ( $r=0.29$ not significantly at the $95 \%$ significance level) is found between changes in D20 and SST changes (Fig. 10b). These results indicated that the role of remote wind forcing in the SST warming will be weak in the EACT region.

Under GLENS, contrary to RCP8.5, we found that changes in the D20 and WEA wind are strongly correlated ( $r=0.88$ at the $95 \%$ significance level) and also a high correlation ( $r=0.79$ at the $95 \%$ significance level) is noted between changes in D20 and SST (Fig. 11a, b). In addition, changes in D20 and SSH are well correlated $(r=0.87$ at the $95 \%$ significance level) (Fig. 11c). Finally, we also found that changes in SSH are very well correlated with SST changes ( $r=0.90$ at the $95 \%$ significance level), and this shows that changes in SST are better correlated with SSH than D20 (Fig. 11b, d). All these results indicated that remote forcing associated to WEA winds changes plays an important role in the EACT SST cooling.

To finish this study, the mean efficacy (ratio of SST_ GLENS_minus SST_RCP8.5 and SST_RCP8.5 minus SST_ Baseline) of SAG to offset the effects of global warming is derived for SST in the EACT region following the previous studies (Da-Allada et al. 2020; Cheng et al. 2019). The efficacy ratio is larger than -1 if changes in the baseline have been compensated by geoengineering relative to baseline, whereas if the ratio is smaller than -1 , then geoengineering induced changes over-compensated baseline conditions. In this study, we find an efficacy ratio of -1.19 for SST in the EACT region, which suggests that SAG will be slightly over effective (a slight over compensation) for SST in the EACT.

\section{Conclusions and discussions}

This study investigates the response of the equatorial Atlantic Cold Tongue to Stratospheric Aerosol Geoengineering using the RCP8.5 scenario. Model results used in the work are from the GLENS project, which used the CESM1 model with Parallel Ocean Program (POP2) and the Whole Atmosphere Community Climate Model (WACCM) as its oceanic and atmospheric components, respectively. Stratospheric sulfur injection is used as a mitigation strategy to reduce the effects of global warming. This study examines SST changes
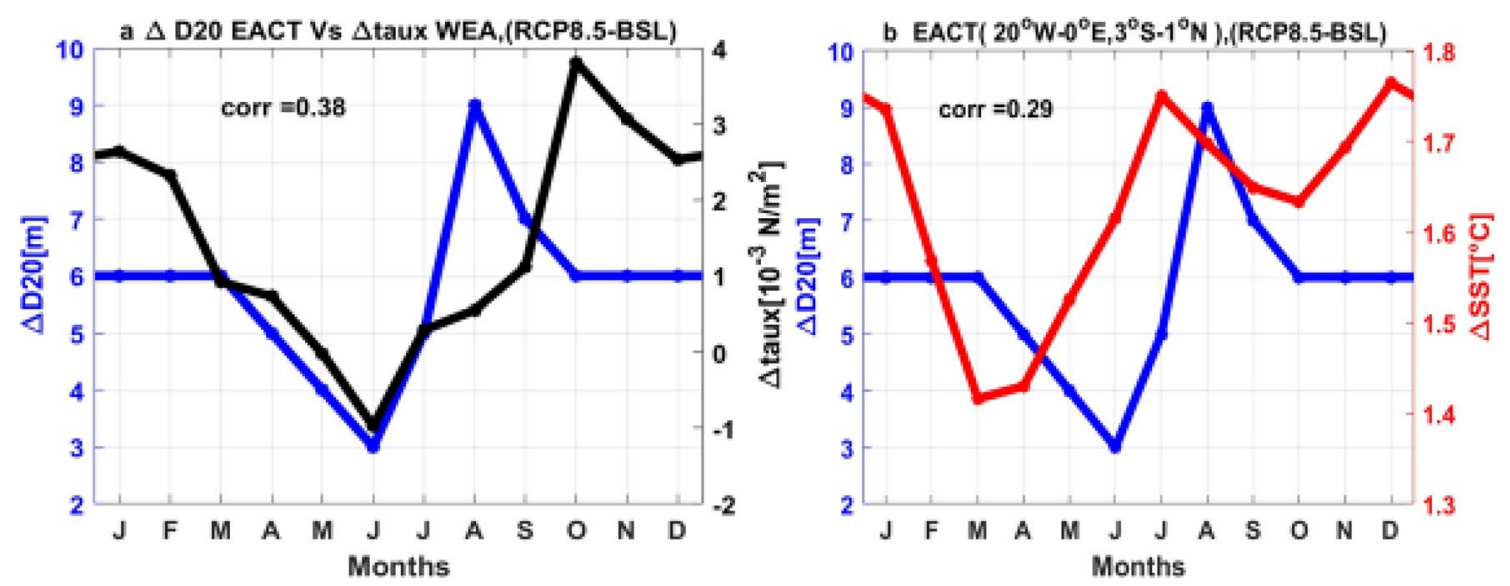

Fig. 10 The seasonal cycles of the changes relative to the baseline under RCP8.5, $\mathbf{a}$ in D20 at EACT (blue curve) versus wind stress at WEA (black curve); b in D20 (blue curve) versus SST (red curve) at EACT 

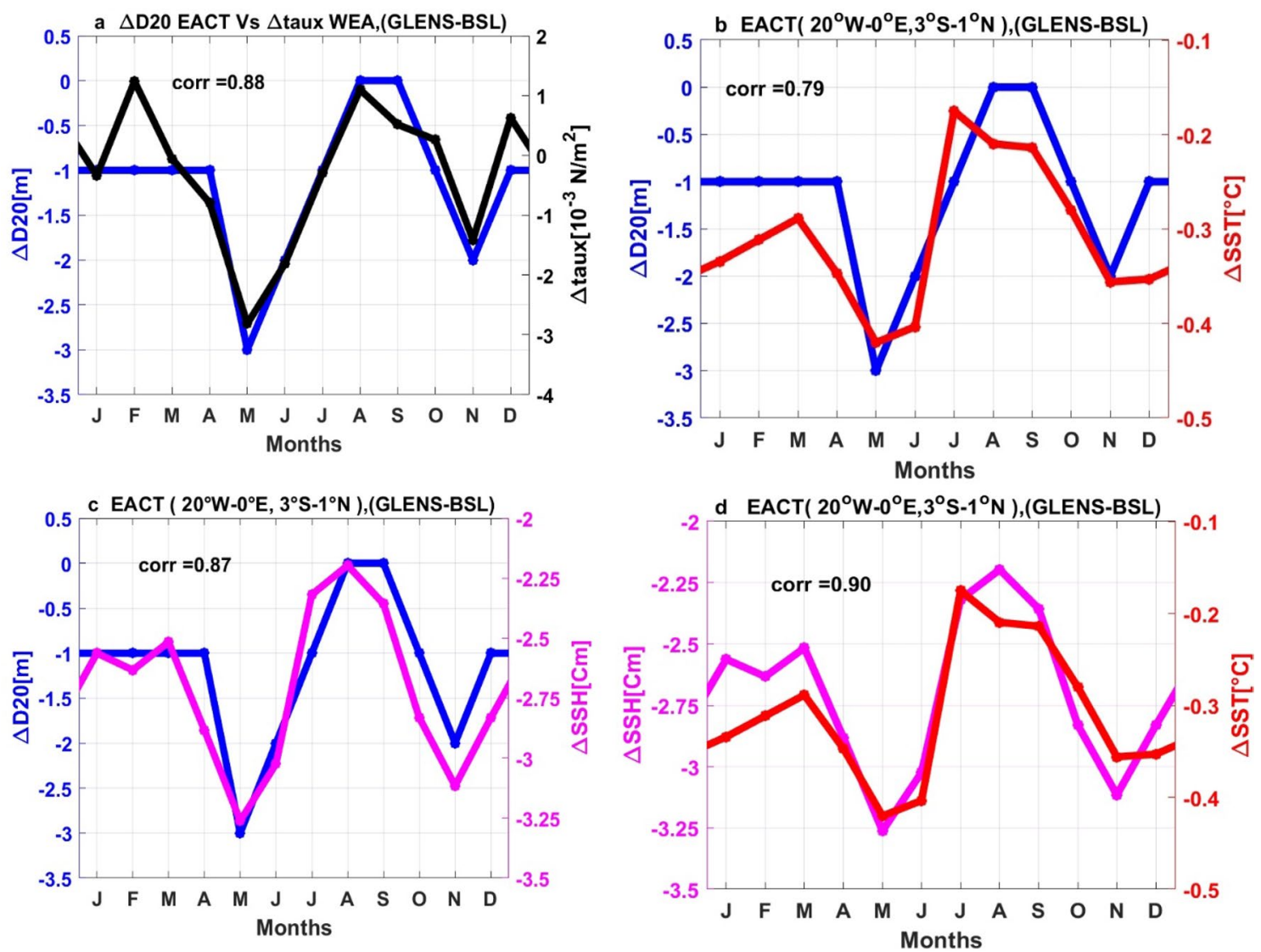

Fig. 11 The seasonal cycles of the changes relative to the baseline, under GLENS, $\mathbf{a}$ in D20 at EACT (blue curve) versus wind stress at WEA (black curve); b in D20 (blue curve) versus SST (red curve) at

EACT, $\mathbf{c}$ in D20 (blue curve) versus SSH (magenta curve) and $\mathbf{d}$ in SSH (magenta curve) versus SST (red curve) at EACT (color figure online)

relatively to the present climate (2010-2029) under RCP8.5 and SAG (2050-2069). The paper also provides the physical processes involved in SST changes.

We showed that the model successfully reproduced the ocean temperatures in the Cold Tongue region despite a slightly warm bias. Our findings reveal that under RCP8.5, the SST (compared to baseline) warms throughout the year with a maximum of $1.7^{\circ} \mathrm{C}$ in July. This warming is mainly due to the weakening of the vertical mixing at the base of the mixed layer (local process). This reduction of the vertical mixing, from July to April is due to the decrease in the vertical shear of the horizontal currents at the base of the mixed layer but is linked to stratification, from May to June. Under SAG, the SST decreases significantly (relative to baseline) all months of the year except in July (where the SST cooling is not significantly) with a maximum cooling value of $-0.4{ }^{\circ} \mathrm{C}$ during the period of Cold tongue (May-June). This SST cooling is largely related to the remote forcing (non-local processes) associated to WEA winds modifications although the contribution of the local processes is not negligible. Our findings are similar with previous works (Cheng et al. 2019; Cao 2018) which

indicate a cooling of the SST under SAG. Finally, in this study, the mean efficacy ratio of geoengineering calculated is -1.19 , and this indicated that the use of SAG is slight over effective (a slight over compensation) for SST in the EACT.

Acknowledgements We would like to acknowledge the financial support of the DECIMALS fund of the Solar Radiation Management Governance Initiative, which was set up in 2010 by the Royal Society, Environmental Defense Fund, and The World Academy of Sciences and is funded by the Open Philanthropy Project. The data used in this study are available to the community via the Earth System Grid (see information at www.cesm.ucar.edu/projects/community-projects/ GLENS/). The CESM project is supported primarily by the National Science Foundation. This work is also in the framework of the Jeune Equipe Associée à l'IRD named Variabilité de la SAlinité et Flux d'eau doUce à MultiÉchelles which is supported by Institut de Recherche pour le Développement (IRD). We also thank Alan Robock for his suggestions to improve this manuscript.

\section{Declarations}

Conflict of interest On behalf of all authors, the corresponding author states that there is no conflict of interest. 
Open Access This article is licensed under a Creative Commons Attribution 4.0 International License, which permits use, sharing, adaptation, distribution and reproduction in any medium or format, as long as you give appropriate credit to the original author(s) and the source, provide a link to the Creative Commons licence, and indicate if changes were made. The images or other third party material in this article are included in the article's Creative Commons licence, unless indicated otherwise in a credit line to the material. If material is not included in the article's Creative Commons licence and your intended use is not permitted by statutory regulation or exceeds the permitted use, you will need to obtain permission directly from the copyright holder. To view a copy of this licence, visit http://creativecommons.org/licenses/by/4.0/.

\section{References}

Bourlès B et al (2008) The PIRATA program: history and accomplishments of the 10 first years tropical Atlantic observing system's backbone. Bull Am Meteorol Soc 89:1111-1125. https://doi.org/ 10.1175/2008BAMS2462.1

Burls NJ, Reason CJC, Penven P, Philander SG (2012) Energetics of the Tropical Atlantic zonal mode. J Clim 25(21):7442-7466. https:// doi.org/10.1175/JCLI-D-11-00602.1

Caniaux G, Giordani H, Redelsperger J-L, Guichard F, Key E, Wade M (2011) coupling between the Atlantic cold tongue and the West African monsoon in boreal spring and summer. J Geophys Res 116:C04003. https://doi.org/10.1029/2010JC006570

Cao L (2018) The effects of solar radiation management on the carbon cycle. Curr Clim Change Rep 4(1):41-50. https://doi.org/10.1007/ s40641-018-0088-z

Castaño-Tierno A, Mohino E, Rodríguez-Fonseca B, Losada T (2018) Revisiting the CMIP5 thermocline in the equatorial Pacific and Atlantic oceans. Geophys Res Lett 45:12963-12971. https://doi. org/10.1029/2018GL079847

Cheng W, MacMartin DG, Dagon K, Kravitz B, Tilmes S, Richter JH et al (2019) Soil moisture and other hydrological changes in a stratospheric aerosol geoengineering large ensemble. J Geophys Res 124:12773-12793. https://doi.org/10.1029/2018JD030237

Crutzen PJ (2006) Albedo enhancement by stratospheric sulfur injections: a contribution to resolve a policy dilemma? Clim Change 77(3-4):211-220. https://doi.org/10.1007/s10584-006-9101-y

Da-Allada CY, Jouanno J, Gaillard F, Kolodziejczyk N, Maes C, Reul N, Bourles B (2017) Importance of the Equatorial Undercurrent on the sea surface salinity in the eastern equatorial Atlantic in boreal spring. J Geophys Res Oceans 122:521-538. https://doi. org/10.1002/2016JC012342

Da-Allada CY, Baloïtcha E, Alamou EA, Awo FM, Bonou F, Pomalegni $Y$ et al (2020) Changes in West African summer monsoon precipitation under stratospheric aerosol geoengineering. Earth's Future 8:e2020EF001595. https://doi.org/10.1029/2020E F001595

Da-Allada CY, Agada J, Baloitcha E, Hounkonnou MN, Jouanno J, Alory G (2021) Causes of the northern Gulf of Guinea cold event in 2012. J Geophys Res 126:e2021JC017627. https://doi.org/10. 1029/2021JC017627

Danabasoglu G, Bates SC, Briegleb BP, Jayne SR, Jochum M, Large WG, Peacock S, Yeager SG (2012) The CCSM4 ocean component. J Clim 25(5):1361-1389. https://doi.org/10.1175/ JCLI-D-11-00091.1

Ding H, Keenlyside NS, Latif M (2010) Equatorial Atlantic interannual variability: role of heat content. J Geophys Res 115:C09020. https://doi.org/10.1029/2010JC006304

Foltz GR, McPhaden MJ (2006) The role of oceanic heat advection in the evolution of tropical North and South Atlantic SST anomalies. J Clim 19(23):6122-6138. https://doi.org/10.1175/JCLI3961.1
Foltz GR, Grodsky SA, Carton JA, McPhaden MJ (2003) Seasonal mixed layer heat budget of the tropical Atlantic Ocean. J Geophys Res 108(5):3146. https://doi.org/10.1029/2002JC001584

Giordani H, Caniaux G, Voldoire A (2013) Intraseasonal mixed-layer heat budget in the equatorial Atlantic during thecold tongue development in 2006. J Geophys Res 118:650-671. https://doi.org/10. 1029/2012JC008280

Halkides D, Lee T (2011) Mechanisms controlling seasonal mixed layer temperature and salinity in the Southwestern Tropical Indian Ocean. Dyn Atmos Oceans 51(3):77-93. https://doi.org/10.1016/j. dynatmoce.2011.03.002

Huang B, Thorne PW, Banzon VF, Boyer T, Chepurin G, Lawrimore JH, Menne MJ, Smith TM, Vose RS, Zhang HM (2014) Extended Reconstructed Sea Surface Temperature Version 4 (ERSSTv4). Part I: upgrades and intercomparisons. J Clim 30(8179):8205. https://doi.org/10.1175/JCLI-D-14-00006.1

Hummels R, Dengler M, Bourlès B (2013) Seasonal and regional variability of upper ocean diapycnal heat flux in the Atlantic Cold Tongue. Prog Oceanogr 111:52-74. https://doi.org/10. 1016/j.pocean.2012.11.001

Irvine P, Emanuel K, He J, Horowitz LW, Vecchi G, Keith D (2019) Halving warming with idealized solar geoengineering moderates key climate hazards. Nat Clim Change 9(4):295-299. https://doi.org/10.1038/s41558-019-0398-8

Jones AC, Hawcroft MK, Haywood JM, Jones A, Guo X, Moore JC (2018) Regional climate impacts of stabilizing global warming at $1.5 \mathrm{k}$ using solar geoengineering. Earth's Future 6:230-251. https://doi.org/10.1002/2017EF000720

Jouanno J, Marin F, du Penhoat Y, Sheinbaum J, Molines J-M (2011) Seasonal heat balance in the upper $100 \mathrm{~m}$ of the equatorial Atlantic Ocean. J Geophys Res 116:C09003. https://doi.org/ 10.1029/2010JC006912

Karami K, Tilmes S, Muri H, Mousavi SV (2020) Storm track changes in the Middle East and North Africa under stratospheric aerosol geoengineering. Geophys Res Lett 47:e2020GL086954. https://doi.org/10.1029/2020GL086954

Kravitz B, Robock A, Boucher O, Schmidt H, Taylor KE, Stenchikov G, Schulz M (2011) The Geoengineering Model Intercomparison Project (GeoMIP). Atmos Sci Lett 12:162-167. https://doi. org/10.1002/asl.316

Kravitz B, Caldeira K, Boucher O, Robock A, Rasch PJ, Alterskjaer K, Karam DB, Cole JNS, Curry CL, Haywood JM, Irvine PJ, Ji D, Jones A, Kristjánsson JE, Lunt DJ, Moore JC, Niemeier U, Schmidt H, Schulz M, Singh B, Tilmes S, Watanabe S, Yang S, Yoon J-H (2013) Climate model response from the Geoengineering Model Intercomparison Project (GeoMIP). J Geophys Res 118:8320-8332. https://doi.org/10.1002/jgrd.50646

Kravitz B, MacMartin DG, Mills MJ, Richter JH, Tilmes S, Lamarque JF et al (2017) First simulations of designing stratospheric sulfate aerosol geoengineering to meet multiple simultaneous climate objectives. J Geophys Res 122:12616-12634. https://doi.org/10.1002/2017JD026874

Kravitz B, Rasch PJ, Wang H, Robock A, Gabriel C, Boucher O, Yoon J-H (2018) The climate effects of increasing ocean albedo: an idealized representation of solar geoengineering. Atmos Chem Phys 18(17):13097-13113. https://doi.org/10.5194/ acp-18-13097-2018

MacMartin DG, Kravitz B, Tilmes S, Richter JH, Mills MJ, Lamarque J-F, Tribbia JJ, Vitt F (2017) The climate response to stratospheric aerosol geoengineering can be tailored using multiple injection locations. J Geophys Res 122:12574-12590. https://doi.org/10. 1002/2017JD026868

Maes C, O'Kane TJ (2014) Seasonal variations of the upper ocean salinity stratification in the Tropics. J Geophys Res Oceans 119:1706-1722. https://doi.org/10.1002/2013JC009366 
Marin F, Caniaux G, Giordani H, Bourlès B, Gouriou Y, Key E (2009) Why were sea surface temperatures so different in the Eastern Equatorial Atlantic in June 2005 and 2006? J Phys Oceanogr 39(6):1416-1431. https://doi.org/10.1175/2008JPO4030.1

Merle J, Fieux M, Hisard P (1979) Annual signal and interannual anomalies of sea surface temperature in the eastern equatorial Atlantic Ocean. Deep-Sea Res. GATE Supplement II to V 26:77-102

Mills MJ, Richter JH, Tilmes S, Kravitz B, MacMartin DG, Glanville AA et al (2017) Radiative and chemical response to interactive stratospheric sulfate aerosols in fully coupled CESM1 (WACCM). J Geophys Res 122:13061-013078. https://doi.org/10.1002/2017J D027006

Mohan S, Mishra S, Sahany S, Behera S (2021) Long-term variability of Sea Surface Temperature in the Tropical Indian Ocean in relation to climate change and variability. Global Planet Change 199:103436. https://doi.org/10.1016/j.gloplacha.2021.103436

Nnamchi HC, Latif M, Keenlyside NS, Park W (2020) A satellite era warming hole in the equatorial Atlantic Ocean. J Geophys Res 125:e2019JC015834. https://doi.org/10.1029/2019JC015834

Peter AC, Le Hénaff M, du Penhoat Y, Menkes CE, Marin F, Vialard J, Caniaux G, Lazar A (2006) A model study of the seasonal mixed layer heat budget in the equatorial Atlantic. J Geophys Res 111:C06014. https://doi.org/10.1029/2005JC003157

Pinto I, Jack C, Lennard C, Tilmes S, Odoulami RC (2020) Africa's climate response to solar radiation management with stratospheric aerosol. Geophys Res Lett 47:e2019GL086047. https://doi.org/10. 1029/2019GL086047

Planton Y, Voldoire A, Giordani H, Caniaux G (2018) Main processes of the Atlantic cold tongue interannual variability. Clim Dyn
50(5-6):1495-1512. https://doi.org/10.1007/s00382-017-37012.hal-01867602

Richter I, Xie S, Wittenberg AT et al (2012) Tropical Atlantic biases and their relation to surface wind stress and terrestrial precipitation. Clim Dyn 38:985-1001. https://doi.org/10.1007/ s00382-011-1038-9

Robock A, Oman L, Stenchikov GL (2008) Regional climate responses to geoengineering with tropical and Arctic $\mathrm{SO}_{2}$ injections. J Geophys Res 113:D16101. https://doi.org/10.1029/2008JD010050

Schlundt M, Brandt P, Dengler M, Hummels R, Fischer T, Bumke K, Krahmann G, Karstensen J (2014) Mixed layer heat and salinity budgets during the onset of the 2011 Atlantic cold tongue. J Geophys Res 119:7882-7910. https://doi.org/10.1002/2014JC010021

Tilmes S et al (2013) The hydrological impact of geoengineering in the Geoengineering Model Intercomparison Project (GeoMIP). J Geophys Res 118(19):11036-11058. https://doi.org/10.1002/ jgrd.50868

Tilmes S, Richter JH, Kravitz B, MacMartin DG, Mills MJ, Simpson IR et al (2018) CESM1 (WACCM) Stratospheric Aerosol Geoengineering Large Ensemble (GLENS) Project. Bull Am Meteorol Soc 99:2361-2371. https://doi.org/10.1175/BAMS-D-17-0267.1

Visioni D, MacMartin DG, Kravitz B, Richter JH, Tilmes S, Mills MJ (2020) Seasonally modulated stratospheric aerosol geoengineering alters the climate outcomes. Geophys Res Lett 47:e2020GL088337. https://doi.org/10.1029/2020GL088337

Wade M, Caniaux G, du Penhoat Y (2011) Variability of the mixed layer heat budget in the eastern equatorial Atlantic during 20052007 as inferred using Argo floats. J Geophys Res 116:C08006. https://doi.org/10.1029/2010JC006683 